\title{
An Argument for Physician-Assisted Suicide and Against Euthanasia Raphael Cohen-Almagor ${ }^{1}$
}

\section{Summary}

The article opens with the hypothesis that the default position that should guide healthcare providers when treating patients at the end of life is that patients opt for life. In the absence of an explicit request to die, we may assume that patients wish to continue living. Thus the role of the medical profession is to provide patients with the best possible conditions for continued living.

The article makes a case for physician-assisted suicide legislation. It examines the 'quality of life' argument, and the issue of the patient's autonomy and competence. It is argued that (1) quality of life is a subjective concept. Only the patient can conclude for herself that her quality of life is so low to warrant ending it, and that (2) only competent patients may request ending their lives. Patients' lives should not be actively terminated by the medical team without the explicit consent of patients.

The article then probes the role of physicians at the end of life, arguing that medicine should strive to cater to the wishes of all patients, not only the majority of them. Physicians should not turn their backs to justified requests by their patients. Physicians are best equipped to come to the help of patients at all stages of their illness, including their end-of-life. At the same time, in ending life, the final control mechanism should be with the patient. Thus physician-assisted suicide is preferred to euthanasia in order to lower the possibility of abuse and of ending the lives of patients without their consent and

\footnotetext{
${ }^{1}$ I thank David Weisstub for his constructive comments.
} 
against their wishes. As matters of life and death are grave, they should be taken with utmost seriousness, requiring the instalment of ample checks against abuse and facilitating mechanisms designed to serve the patient's best interests. The article concludes with nineteen careful and detailed guidelines for physician-assisted suicide. These are necessary measures designed to ensure that the best interests of the patients are served as they wished.

Key words: autonomy; dignity; end-of-life; euthanasia; physician-assisted suicide; quality of life

\section{Introduction}

During one of my conversations with Isaiah Berlin we discussed end-of-life issues. Isaiah told me a personal story about one of his friends who, at that time, experienced some health problems. Later he reflected on our discussion in writing. Isaiah wrote:

My friend did indeed collapse, his leg was cut off, he did not eat because he could not. He expressed no wish to die. The doctors saved him; he is still in a bad state but is unaware of it, and is quite cheerful. He proposes to go on living, but this is unlikely to last long. ${ }^{2}$

\footnotetext{
${ }^{2}$ Letter of Isaiah Berlin to R. Cohen-Almagor (6 February 1995).
} 
This letter encapsulates some of the major concerns at the end-of-life. These concerns can be formulated in questions:

- What is the patient's condition?

- What are the patient's wishes?

- What do we mean by "quality-of-life"?

- What is the significance of the patient's autonomy and competence?

- What are the roles of the medical profession at the end-of-life?

In this article, I will unfold these questions, addressing two additional questions:

- Whether we should have end-of-life legislation which includes euthanasia and/or physician-assisted suicide, and

- What might be the impact of such legislation on society?

This article makes a case for physician-assisted suicide legislation. Such legislation should be put under close scrutiny and examined on an annual basis. If the alarm sounds of the opposition prove to be justified, then it will be the task of the medical profession and the legislature to secure remedies against premature killing. In France, the Conseil national de l'Ordre des médecins (CNOM, the national council of the college of physicians) has endorsed euthanasia, ${ }^{3}$ and the French parliament has opened a debate

${ }^{3}$ Cook M, French doctors endorse euthanasia. BioEdge. 2013; 15 February. 
on euthanasia in January $2015 .{ }^{4}$ In the past, President Francois Hollande affirmed his aim to legalise voluntary euthanasia and called for a national debate on the issue. ${ }^{5}$ Indeed, in France and other parts of the world the discussion should continue in earnest, reflecting on changes in reality and always aspiring to protect the patients' best interest.

\section{The Patient's Condition and Wishes}

Discussions about the appropriate treatment at the end-of-life should be reserved to patients who are suffering from an incurable disease, whose quality-of-life is deemed by the patients themselves as low, when death becomes for them an attractive proposition. In most cases, such discussions are reserved to cancer patients. Cancer is a very painful condition and some patients find it intolerable. ${ }^{6}$

${ }^{4}$ Cook M, French parliament begins debate on euthanasia. BioEdge. 2015: 24 January.

${ }^{5}$ Cook M, France to vote on euthanasia later this year. BioEdge. 2013: 6 July; Heneghan T. France aims to allow euthanasia despite ethics doubts. Reuters 2013: 1 July, http://in.reuters.com/article/2013/07/01/france-euthanasia-idINDEE9600HF20130701 [Accessed 2 April 2015].

6 Cook M, 15\% rise in Dutch euthanasia deaths. BioEdge. 2014: 11 October, http://www.bioedge.org/index.php/bioethics/bioethics_article/11172 [Accessed 2 April 2015]; Swildens-Rozendaal WJC. Regional Euthanasia Review Committees - Annual Report 2011 (The Hague, August 2012); Steck N, Junker C, Maessen M, et al., Suicide assisted by right-to-die associations: a population based cohort study. International 
Unfortunately, current medical knowledge has not mastered adequate treatment to many forms of cancer. When a patient's life is saturated with pain, when the entire existence is focused on one's suffering and on means to provide relief for suffering, the normally high value ascription to life deteriorates, and thoughts about the alternative to life might become dominant.

Most patients would like to continue living. As in the Isaiah Berlin story, empirical research has been showing that the yearning to live is very strong. I have visited more than thirty hospitals in Israel, England, Canada, USA, Australia, New Zealand, the Netherlands and Belgium. Most patients, even in the most dreadful conditions, opt for life. This is more so when patients are Catholic, Jews and Muslims. ${ }^{7}$ This is less so in the Netherlands and Flemish-Belgium. ${ }^{8}$ But the general picture is clear: We all possess a zeal for life. Therefore, whenever we are unclear about the patients' wishes, the default position we should take is that the patients

Journal of Epidemiology. 2014 http://ije.oxfordjournals.org/content/early/2014/02/17/ije.dyu010.full [Accessed 2 April 2015].

${ }^{7}$ Cohen-Almagor R, The Right to Die with Dignity: An Argument in Ethics, Medicine, and Law. Piscataway, NJ.: Rutgers University Press; 2001.

${ }^{8}$ Cohen-Almagor R, Euthanasia in the Netherlands: The Policy and Practice of Mercy Killing. Dordrecht: Springer-Kluwer; 2004 and Euthanasia policy and practice in Belgium: Critical observations and suggestions for improvement. Issues in Law and Medicine. 2009; 24(3): 187-218. 
opt to live..$^{9}$ Only a small minority of patients expressly wish to die. Thus our starting hypothesis is:

Hypothesis: The default position is that patients opt for life. In the absence of an explicit request to die, we may assume that patients wish to continue living. Thus the role of the medical profession is to provide patients with the best possible conditions for continued living.

\section{'Quality of Life'}

Many of the supporters of euthanasia advance the quality-of-life argument. ${ }^{10}$ The term 'quality of life' has many positive connotations when used in a general social context. For instance, we speak of improving the quality of citizens' lives by providing them job opportunities, cultural events, and by making efforts to decrease air pollution. People use the term 'quality of life' when describing the different ways they advance their comfort, their status and their tranquillity. Likewise, in medicine the term 'quality of life' has positive connotations, for example in rehabilitation, physiotherapy, cosmetic treatments, palliative care, psychiatry and psychology. However, when we deal with end-of-life issues, ethicists who side with euthanasia use the term 'quality of life' in a negative sense more often than

\footnotetext{
${ }^{9}$ See Israel Dying Patient Law, Chapter C, Section 4 (15 December 2005).

${ }^{10}$ Harris J. The Value of Life. London: Routledge and Kegan Paul; 1985; Kuhse H. Quality of life and the death of 'Baby M'. Bioethics. 1992; 6(3): 233-250; Singer P. Practical Ethics. New York: Cambridge University Press; 1993.
} 
in a positive one, meaning that they do not seek to improve the patient's life but to end it. ${ }^{11}$ In their discussions, the 'quality of life' concept often serves to justify the termination of life. Even supporters of euthanasia and of granting the patient a right to decide her own destiny express suspicion regarding this concept. In his testimony before the House of Lords Select Committee on Medical Ethics, Ronald Dworkin explicitly denounced 'quality of life' as "a mischievous term", saying clearly: "I do not like it very much". Dworkin explained that the term 'quality' suggests some sort of felt experience or pleasure - how much pleasure is being felt. Instead he would like to refer to the idea of a 'good life' where 'good' is not merely a matter of how it feels, but it is also a matter of a structure, a narrative. ${ }^{12}$

'Quality of life' is a subjective concept: one's quality of life is determined by one's personal life circumstances. There is a place to consider the quality of a particular life, but the decision as to what considerations constitute justifications for termination of that life should be left to the patient. We need to distinguish between situations in which the justification for terminating life is voiced by the patients themselves, and situations in

${ }^{11}$ Kuhse H. The Sanctity of life Doctrine in Medicine: A Critique. Oxford: Clarendon Press; 1987; Kuhse H. and Singer P. Should the Baby Live? The Problem of Handicapped Infants. Oxford: Oxford University Press; 1985.

12 Ronald Dworkin's testimony (29 June 1993), in House of Lords, Select Committee on Medical Ethics, session 1993-94, Minutes of Oral Evidence. London: HMSO; 1994, at 161. For further discussion, see Cohen-Almagor $R$, and Shmueli $M$, Can life be evaluated? The Jewish Halachic approach vs. the Quality of Life Approach in medical ethics: A critical view. Theoretical Medicine and Bioethics. 2000; 21(2): 117-137. 
which other parties - physicians, nurses, hospital managers, ethicists, relatives - postulate justifications for terminating patients' lives. Whenever possible, each individual should decide for herself what constitutes a life of quality, and at what point it becomes devoid of quality or essence. As in the Berlin story, no one else should conclude for a patient that her life is meaningless when she finds some value in it, just as no one else should demand to prolong life at all costs when the patient herself asks for her death. The objection to paternalism on this issue is absolute.

This is not to say that a life devoid of certain distinguishing features (consciousness, self-responsibility, human dignity), or a life in which certain features are present (suffering and pain) is necessarily void of quality. A patient may decide that in the absence of certain quality characteristics her life is no longer worth living. For example, some may think that a life devoid of consciousness or devoid of memory (dementia) is not a meaningful life. Patients experiencing some suffering might complain of loss of human dignity. But others may think that their dignity is preserved even as they experience unimaginable suffering. While some may see life in terms of an absolute value others may perceive life differently. Some perceive life as a means to achieve selffulfillment, to develop human abilities, to experience discoveries, thrills, and achievements. Some think that life in itself is of no value, but rather is a precondition for the existence of any value whatsoever. When denied the ability to actualize their choice, some people find no reason to live. The dreariness and distress in which they live could lead them to the conclusion that death is preferable. 
Argument One: Quality of life is a subjective concept. Only the patient can conclude for herself that her quality of life is so low to warrant ending it.

\section{Patient's Autonomy and Competence}

The decision whether to preserve a life or to terminate it should remain in the hands of the patient when she is able to express such an opinion. The liberal state should help preserve life. The liberal state should not insist on prolonging the lives of patients who feel that such an action would negate their dignity. The issue is far more complex when patients are unable to express an intelligible and autonomous opinion, be it because they are young, mentally defective, or unconscious. Such patients are lacking autonomy and ability to determine their destiny.

When adult and no-longer-autonomous patients are concerned, we must first examine whether they had stated an opinion about extending a life after their autonomy was lost. If the patients had explicitly and clearly stated in writing and/or recording (audio, video) that they were not interested in prolonging life under such conditions, their opinion should be respected. In the event, however, that the patients stated previously that upon reaching a certain future state of illness they would prefer to die, but when they actually reached that state they show signs of preferring to cling to life, we must respect their present choice. Building on the Berlin story, a patient may state that in case of deterioration of her physical and mental condition beyond recognition, she would prefer to die. Upon reaching an advanced stage of atrophy, however, she nonetheless shows signs of happiness when seeing her relatives, or expresses some interest in, say, flowers, food or her friends, it may be concluded that the patient finds some value in her present 
unfortunate condition. Therefore, we must ignore prior instructions to the contrary and allow the continuation of her life. ${ }^{13}$ People have the right to change their minds and we should not deny them that right. In accordance with Hypothesis One, it is always better to err on the side of life.

If it is not possible to determine the patient's past and present desires, and there are no signs that the patient wishes to continue living, then the decision should be made by the medical team in cooperation and consultation with those who are close to the patient: blood relatives, her friends and other beloved people. By "beloved people" it is meant the people around the patient's bed, those who care about the patient, who devote their time and energies to contribute to the patient's well-being.

The Benelux countries (The Netherlands, Belgium and Luxemburg) and recently (2014) the Canadian region of Quebec ${ }^{14}$ have legislated euthanasia. Among the worrying data in all the Dutch euthanasia reports from 1990 until the present is that 0.2-0.8 percent of deaths were the result of the use of lethal drugs, not at the explicit request of the patient. There were 1000 cases (0.8\%) without explicit and persistent request in 1990, and 900

${ }^{13}$ For a contrasting view see Dworkin R. Life's Dominion. New York: Knopf; 1993.

14 Quebec Bill 52, An Act respecting end-of-life care, 2014, http://www.patientsrightscouncil.org/site/wp-

content/uploads/2014/06/Canada_Bill_52_14-052a_-passed_06_05_14.pdf [Accessed 2 April 2015]. 
such cases $(0.7 \%)$ in $1995 .{ }^{15}$ This number remained unchanged in 2001. In 2005 , there were 550 cases $(0.4 \%) .{ }^{16}$ Ending of life without a patient's explicit request occurred most frequently among people dying at an age younger than 65 years. ${ }^{17}$ Physician-assistancein-dying without an explicit request by the patient may have involved patients who were not able to express their wishes, such as neonates or comatose patients; patients whose competency to express well-considered preferences was doubtful, such as patients with dementia or psychiatric disorders; or competent patients for whom physician-assistancein-dying was the result of an implicit request or an agreement to hasten death. ${ }^{18}$ The 2010

${ }^{15}$ van der Wal G, and van der Maas PJ. Empirical research on euthanasia and other medical end-of-life decisions and the Euthanasia Notification Procedure. In Thomasma DC, Kimbrough-Kushner T, Kimsma GK, and Ciesielski-Carlucci C. (eds.), Asking to Die. Dordrecht: Kluwer Academic Publishers; 1998: 171.

${ }^{16}$ van der Heide A, Onwuteaka-Philipsen BD, Rurup ML, et al. End-of-life practices in the Netherlands under the Euthanasia Act. N Engl J Med. 2007; 356: 1957-1965; den Hartogh G, The regulation of euthanasia: how successful is the Dutch system?. In Youngner SJ. and Kimsma GK (eds.). Physician-Assisted Death in Perspective: Assessing the Dutch Experience. Cambridge: Cambridge University Press; 2012: p. 366. 17 Onwuteaka-Philipsen BD, et al., Euthanasia and other end-of-life decisions in the Netherlands in 1990, 1995, and 2001.Lancet. 2003; 362: 2 August, p. 397.

18 van der Heide A, Physician-assistance in dying without an explicit request by the patient. In Youngner SJ. and Kimsma GK (eds.). Physician-Assisted Death in Perspective: Assessing the Dutch Experience. p. 137. 
report shows that ending the patient's life without an explicit request declined from $0.4 \%$ to $0.2 \% .{ }^{19}$ It is reiterated that under Dutch law, it is illegal to terminate life when the patient is not fully competent.

In Belgium, A 1998 study conducted in Flanders showed that decisions to end life were common among general practitioners. In Flanders, where $60 \%$ of the Belgian population resides, more than $5 \%$ of all deaths in general practice (some 1200 cases) resulted from the use of drugs with the explicit intention of shortening the patient's life. ${ }^{20}$ The rate of administration of lethal drugs to patients without their explicit request was 3.2 percent. ${ }^{21}$ The Euthanasia Act came into force in 2002. Eight years later in 2010, the use of life-ending drugs without explicit request was recorded in $1.8 \%$ of deaths ${ }^{22}$ and in 2013

${ }_{19}$ Onwuteaka-Philipsen BD, Brinkman-Stoppelenburg A, Penning C, et al, Trends in endof-life practices before and after the enactment of the Euthanasia Law in the Netherlands from 1990 to 2010: a repeated cross-sectional survey. Lancet. 2012; 380(9845): 908-15. ${ }^{20}$ Bilsen J, Vander Stichele R, Mortier F, et al., The incidence and characteristics of endof-life decisions by GPs in Belgium. Family Practice. 2004; 21(3): 283, 286.

21 Deliens L, Mortier F, Bilsen J, et al., End-of-life decisions in medical practice in Flanders, Belgium: A nationwide survey. Lancet. 2000; 356: 1806.

22 Chambaere $\mathrm{K}$, Bilsen $\mathrm{J}$, Cohen $\mathrm{J}$, et al., Physician-assisted deaths under the Euthanasia Law in Belgium: a population-based survey. Canadian Medical Association Journal. 2010; 182(9): 896. 
it was $1.7 \%$ of deaths. ${ }^{23}$ These rates are higher than that recorded in 2001 (1.5\%) but they are significantly lower than the rate recorded in 1998 before the legislation of the Euthanasia Act (3.2\%). ${ }^{24}$ Use of life-ending drugs without explicit request involved patients who were 80 -year old or older (52.7\%), those with a disease other than cancer (67.5\%), and those in hospital (67.1\%). The decision was not discussed with the patient in $77.9 \%$ of cases. Physicians explained that the decision was not discussed because the patient was comatose $(70.1 \%)$, had dementia $(21.1 \%)$ or because discussion would have been harmful to the patient's best interest $(8.2 \%){ }^{25}$ It should be reminded that the law specifically stipulates that "the patient is an adult or an emancipated minor, capable and conscious at the time of his/her request," ${ }^{26}$ thus lives of comatose and demented patients

${ }^{23}$ Chambaere K., Vander Stichele R., Mortier F. et al., Recent trends in euthanasia and other end-of-life practices in Belgium, N Eng J Med. 2015; 372 (March): 1179.

${ }^{24}$ Bilsen J, Cohen J, Chambaere $\mathrm{K}$, et al., Medical end-of-life practices under the Euthanasia Law in Belgium, NEJM, 361 (2009); Chambaere K, Bilsen J, Cohen J, et al., Physician-assisted deaths under the Euthanasia Law in Belgium: a population-based survey. Canadian Medical Association Journal. 2010; 182(9): 900.

${ }^{25}$ Chambaere K, Bilsen J, Cohen J, et al., Physician-assisted deaths under the Euthanasia Law in Belgium: a population-based survey. Canadian Medical Association Journal. 2010; 182(9): 895-896.

${ }^{26}$ Belgian Act on Euthanasia, Chapter II, Section 3, no. 1, 
should not be terminated under the Euthanasia Act. It should also be noted that ending the lives of patients without their request is taking place in Belgium more than in all other countries that document such practice, including the Netherlands. ${ }^{27}$

Physicians were asked when they end the lives of patients without explicit request and the answers were in two situations: Shortening the length of the patient's final phase of agony during the last phase of the dying process, and facilitating the death of the "terminally ill, demented and inhumanly deteriorated patient". ${ }^{28}$ Their aims are to shorten the length of misery considered to be futile, ensure a relatively comfortable death and, most worryingly, alleviate the burden of the next of kin. ${ }^{29}$

http://www.ethical-perspectives.be/viewpic.php?LAN=E\&TABLE=EP\&ID=59 [Accessed 2 April 2015].

${ }^{27}$ van der Heide A, Onwuteaka-Philipsen BD, Rurup ML, et al. End-of-life practices in the Netherlands under the Euthanasia Act. N Engl J Med. 2007; 356: 1957-1965; for comparative discussion, see van der Heide A, Deliens L, Faisst K, et al., End-of-life decision-making in six European countries: Descriptive study. Lancet. 2003; 362: 345-50. ${ }^{28}$ Sercu M,, Pype P, Christiaens T, et al, Are General Practitioners prepared to end life on request in a country where euthanasia is legalised?, J Med Ethics. 2012; 38: 277.

29 Ibid. For further discussion, see Pivodic L, Van den Block L, Pardon K, et al., Burden on family carers and care-related financial strain at the end of life: a cross-national population-based study. The European Journal of Public Health. 2014; 24(5): 819-826; 
The liberal state has an obligation to protect the vulnerable. Given that ending patients' lives without request is more common than euthanasia, ${ }^{30}$ and the significant number of terminal sedation cases, it is suggested to urge the Dutch and Belgian medical profession to consider physician-assisted suicide (PAS), a practice that is not common in The Netherlands and in Belgium, ${ }^{31}$ instead of euthanasia. About 2 percent of Dutch and Belgians die with euthanasia, where the physician administers the lethal drugs (i.e. the last act is performed by the physician), and less than 0.1 percent by physician-assisted suicide, where the patient ingests the lethal drug provided by the physician (i.e. the last act is performed by the patient). ${ }^{32}$ Although 34 percent of Dutch general practitioners prefer assisted suicide, only 22 percent offer the two options to the patients requesting

R. Cohen-Almagor, "First Do No Harm: Shortening Lives of Patients without Their Explicit Request in Belgium", Journal of Medical Ethics, Vol. 41 (2015): 625-629.

${ }^{30}$ van der Heide A, Deliens L, Faisst K, et al., End-of-life decision-making in six European countries: Descriptive study. Lancet. 2003; 362: 345-50.

31 Ibid.

${ }^{32}$ Bilsen, J., Cohen J., Chambaere K., et al. Medical end-of life practices under the euthanasia law in Belgium. The New England Journal of Medicine. 2009; 361(11): 11191121. 
assisted dying. ${ }^{33}$ While morally speaking euthanasia may be warranted, ${ }^{34}$ the fear of abuse is substantial. A fine line distinguishes between moral consideration and the implementation of a policy. As shown, research conducted in the Netherlands and in Belgium does not convince that both countries have properly addressed abuse concerns. Many patients are still killed involuntarily. The Dutch and Belgians are researching the way their dying patients are being handled in a medical context. Their cultures of selfsearching are certainly necessary. Until we can be sure that euthanasia is not abused on a policy level, control should remain with patients, not with physicians. PAS ensures that end-of-life procedures are restricted only to competent patients.

Argument Two: Only competent patients may request ending their lives. Patients' lives should not be actively terminated by the medical team without the explicit consent of patients.

\section{The Role of Physicians}

Now we need to discuss the troubling issue of whether or not it is within the physician's responsibility to terminate life. Physicians who are opposed to active euthanasia find no

${ }^{33}$ Bernheim JL, Distelmans W, Mullie A, Questions and Answers on the Belgian Model of Integral End-of-Life Care: Experiment? Prototype? Bioethical Inquiry. 2014; 11: 507-529. ${ }^{34}$ Schuklenk U, Van Delden JJM, Downie J, et al., End-of-life decision-making in Canada: The Report by the Royal Society of Canada Expert Panel on End-of-Life Decision-Making. Bioethics. 2011; 25(S1): 1-73. 
dignity in killing a patient, and express anxiety about the character of a society in which doctors assume such a responsibility. ${ }^{35}$ Many physicians believe that their role does not include killing. They argue that (a) if society accepts the need for active euthanasia then such an act can be committed by any person. (b) Society must not make physicians its official executioners. (c) The physician's role is to heal, to help patients and to relieve their suffering. (d) Physicians should not be assigned the additional task of execution.

In response let me first demur and say that I resent the use of the term 'executioner.' Support for active euthanasia is not associated with the acceptance of execution in society. One of the physician's roles is, indeed, to ease patients' suffering. The daily practice in hospitals demonstrates that sometimes the only way to achieve this objective also shortens the patient's life. We are dealing with a population of patients with reasons, drives and wills. Failing to listen to those reasons, drives and wills would lead to gross paternalism: an unjustified action that takes the responsibility from the patient. Such behaviour is unjustified because (a) the person for whom the physician acts paternalistically is competent, and (b) the conduct in question is involuntary and coercive. Is it the task of a physician to keep a person alive against that person's will? How do we answer that small group of patients who have lost their appetite for life and plead for their doctors for help? While some may argue that it is not among the physician's responsibilities to provide mercy killing, the questions then are whether we should ignore

${ }^{35}$ Culzac N, Assisted dying bill could create 'death squads' of doctors, cancer specialist says, while PM 'not convinced'. The Independent (17 July 2014); Sprung CL, Eidelman LA, Steinberg A, Is the physician's duty to the individual patient or to society? Critical Care Medicine. 1995; 23(4): 618-620. 
the patient's wishes and whether another professional body exists in society that could take responsibility for this troubling task.

As for the first question, if physicians ignore the patients' wishes, patients are left with the option of committing suicide. However, many patients are reluctant to do so because they are anxious about the possibility of waking up to an even more dreadful condition. Failing to take the adequate medication, or the adequate dose of medication, their condition might deteriorate further, their quality-of-life reduced, and they would still be alive. Patients need the assistance of the medical profession.

As for the second question, whether it is conceivable to ask another association or social group (family and close ones of the patient) to assume this responsibility, my answer is conclusive. It is impossible to act on matters of health without medical opinion. I see no escape from including physicians in the decision-making process. While I seek an answer for all patients, including those who wish to die, those who object to active involvement of physicians in ending patients' lives ignore those patients who suffer from incurable diseases and express their wish to die. Obviously those who are opposed to euthanasia should not be expected to commit an act that contradicts their conscience; that would be as paternalistic as ignoring the patient's will. However, there are physicians who might agree with this line of reasoning and who would not necessarily regard active euthanasia as contrary to their medical and moral conscience.

Argument Three: Medicine should strive to cater to the wishes of all patients, not only the majority of them. Physicians should not turn their backs to justified requests by their 
patients. Physicians are best equipped to come to the help of patients at all stages of their illness, including their end-of-life.

\section{Euthanasia v. Physician-assisted Suicide}

Before my first research fieldtrip to the Netherlands, my thesis was pro-euthanasia. This was no longer the case after that trip. Faced with evidence about abuse, I could no longer support euthanasia. I still think that there are cases where euthanasia might be warranted. Philosophically speaking, a strong ethical argument for the practice can be made. But in the realm of practice, upon witnessing the Dutch cavalier view on death and dying, I could no longer support such a policy. Policy is for the entire society, not for specific cases. Indeed, policy might affect specific people and disservice them, harming their best interest. I am unable to endorse such a dangerous policy. ${ }^{36}$

${ }^{36}$ Gomez CF, Regulating Death. New York: The Free Press, 1991; Keown J, Euthanasia in the Netherlands: Sliding down the slippery slope?, Notre Dame J. of Law, Ethics and Public Policy. 1995; 9: 407-448; Hendin H, Seduced by Death. New York: W.W. Norton, 1997; Jochemsen H, Keown J, Voluntary euthanasia under control? Further empirical evidence from the Netherlands. Journal of Medical Ethics. 1999; 25: 16-21; Keown J, Euthanasia, Ethics and Public Policy: An Argument Against Legalisation. Cambridge: Cambridge University Press, 2002; Sheldon T, Dutch doctors speak out about past errors to change culture on patient safety. BMJ. 2009; 339: b5338; Beckford M, Fearful elderly people carry 'anti-euthanasia cards'. The Telegraph (21 April 2011), http://www.telegraph.co.uk/health/healthnews/8466996/Fearful-elderly-people-carry- 
Delineating the legislation within the confines of physician-assisted suicide is designed to prevent abuse. The last act should lie squarely with the patient who drinks or eats the lethal poison, prepared by the physician. It is the patient who commits suicide with the help of the physician. The physician mixes the lethal medication in a yogurt or a pudding, and the patient eats it by herself. If the patient did not give consent, she should not be manipulated or forced to take the poison or take it without knowing. Furthermore, the vast majority of patients who request death are cancer patients who are able to swallow. ${ }^{37}$ For the small minority of patients who are unable to swallow, I agree that keeping them alive in a state of suffering against their will would be cruel. Documented and explained reasoning for making exception to the rule could be made to warrant euthanasia in such special and few circumstances.

anti-euthanasia-cards.html [Accessed 2 April 2015]; Haerens M, Euthanasia. San Diego: Greenhaven Press; 2015.

${ }^{37}$ Pardon K, Chambaere K, Roeline $\mathrm{H}$, et al., Trends in end-of-life decision making in patients with and without cancer. $J$ of Clinical Oncology. 2013; 31(11): 1450-1457; de Diesbach E, de Loze M, Brochier C, Montero E, Euthanasia in Belgium: 10 years on. European Institute of Bioethics (Brussels, 2012); Cook M, 15\% rise in Dutch euthanasia $\begin{array}{llll}\text { deaths. } & \text { BioEdge. } & 11 & \text { October }\end{array}$ http://www.bioedge.org/index.php/bioethics/bioethics_article/11172 [Accessed 2 April 2015]; Swildens-Rozendaal WJC, Regional Euthanasia Review Committees - Annual Report 2011 (The Hague, August 2012). 
As a supporter of physician-assisted suicide, I believe that for some patients this is the preferred and the right option. Some strong-willed patients would like to decide the time of their death. Only they can say: "Enough is enough. Now it is time to say good bye, because I can no longer cope with my state, and because medicine does not have a cure for me." Physician-assisted suicide can be the solution especially for suffering cancer patients, at the last stage of their lives. It is humane to cater to these people, enabling them to die at their own bed, in the company of their loved-ones.

The Dutch and the Belgians do not pay much notice to the distinction between voluntary physician-assisted suicide and active euthanasia. I believe the distinction is important and viable. Physician-assisted suicide provides control to the patients until the very last moment of their lives, prevents possible abuse, and assures that they indeed wanted to die. Restricting aid-in-dying legalization to physician-assisted suicide seems to limit the number of hastened deaths and their increase over time. This might be partly due to a higher psychological threshold towards assisted suicide and more stringent procedural rules excluding non-terminally ill patients. ${ }^{38}$ It is reiterated that in most cases patients are able to do the final act to terminate their lives. In the rare occasions of

${ }^{38}$ Gamondi C, et al., Legalisation of assisted suicide: a safeguard to euthanasia?, Lancet. 2014; 384(9938) (July): 127. 
complete paralysis or suffocation, when the patient is absolutely unable to activate the lethal needle, only then the doctor may do the final act of mercy. ${ }^{39}$

Argument Four: In ending life, the final control mechanism should be with the patient. Thus physician-assisted suicide is preferred to euthanasia in order to lower the possibility of abuse and of ending the lives of patients without their consent and against their wishes.

\section{For and Against Physician-assisted Suicide Legislation}

Those who oppose aid-in-dying legislation argue that it is too risky. Such legislation might change the medical culture and harm patients, especially vulnerable populations. The opposition emphasises that only very few patients ask to end their lives, thus it is not prudent to change the nature of medicine to include killing for the sake of the few. The role of the medical profession is, and should remain, healing. ${ }^{40}$

On the other hand, those who endorse aid-in-dying legislation perceive it as a health right and as a human right. Medicine should assist those who wish to decide the moment of their death. They maintain that the roles of medicine are not fixed but rather

${ }^{39}$ Cohen-Almagor R, The Right to Die with Dignity: An Argument in Ethics, Medicine, and Law. Piscataway, NJ.: Rutgers University Press; 2001; Cohen-Almagor R, Belgian Euthanasia Law: A critical analysis, Journal of Medical Ethics. 2009; 35(7): 436-439.

40 Doughty S, Don't make our mistake: As assisted suicide bill goes to Lords, Dutch watchdog who once backed euthanasia warns UK of 'slippery slope' to mass deaths. Mail Online 9 July 2014. 
in flux. In the past, abortion was prohibited. ${ }^{41}$ At present, genetic enhancement poses new challenges. ${ }^{42}$

Supporters of aid-in-dying legislation take very seriously the "change of culture" argument. There are, indeed, risks involved in such legislation. The aid-in-dying motivation is to help patients in need, not to open the road for abuse. They think that it is possible to install sufficient safeguards against abuse. And if the culture will change and cases of abuse recorded, then the legislature should be called into action to amend the law and secure ample solutions. Life-and-death must be put under a close scrutiny. Sufficient control mechanisms should be in place. End-of-life procedures should be monitored on an annual basis, analysing developments and ascertaining that vulnerable patients are not put at risk. Tellingly, the Oregon Hospice Association that initially opposed the PAS legislation, found no evidence that assisted dying in Oregon has undermined end-of-life care or harmed the best interests of vulnerable populations. ${ }^{43}$

41 The Hippocratic Oath holds: "I will not give a woman a pessary to cause an abortion". http://www.nlm.nih.gov/hmd/greek/greek_oath.html [Accessed 2 April 2015].

42 Genetic Enhancement, http://www.genome.gov/10004767 [Accessed 2 April 2015]; Savulescu J, and Bostrom N, (eds.), Human Enhancement. Oxford: Oxford University Press; 2009; Savulescu J, Ter Meulen R, and Kahane G, (eds.), Enhancing Human Capacities. Oxford: Wiley-Blackwell; 2011.

${ }^{43}$ Delamothe T, Snow R, and Godlee F, Why the Assisted Dying Bill should become law in England and Wales. BMJ; 349 (2 July 2014): 1-2. 
While I think medicine should attempt to cater for the needs of all patients, and that a humane death is one in which the patients die at home, surrounded by their loved ones, I am not certain that physician-assisted suicide is warranted for each and every society. End-of-life practices should be just in theory and also just in its application. If the risks are too high, if PAS legislation might change the medical practice for worse as far as patients are concerned, then it should be amended, overhauled or abandoned. The discussion should continue in earnest.

Argument Five: Life and death concerns are grave. They should be taken with utmost seriousness, requiring the instalment of ample checks against abuse and facilitating mechanisms designed to serve the patient's best interests.

\section{Guidelines for Physician-assisted Suicide (PAS)}

The right to die with dignity includes the right to live with dignity until the last minute and the right to part from life in a dignified manner. There are competent, adult patients who feel that the preferred way for them to part from life is through physician-assisted suicide.

I wish to promote physician-assisted suicide because I recognize that individuals should have the power to decide end-of-life issues, and because I oppose euthanasia. I developed these guidelines following fieldtrips to Israel, the United Kingdom, The Netherlands and Belgium. Let me conclude with the following recommendations and suggestions: 
Guideline 1. Physicians are best equipped in terms of knowledge and expertise to provide aid-in-dying. It is the only profession that could come to aid patients who insist on having their right to die. The medical profession is in flux. The rapid scientific and technological progress, the rise of chronic disease, the ability to keep chronic patients alive for many years, and the democratization of knowledge are all important in the shaping of medicine. The medical profession should be attentive to wishes of all patients, and strive to accommodate their wishes.

Guideline 2. The physician should not suggest assisted-suicide to the patient. Instead, it is the patient who should have the option to ask for such assistance. Initiation by the physician might undermine the trust between the patient and the physician, conveying to patients that the physician is giving up on them and values their lives only to the extent of offering assistance to die. Such an offer might undermine the will to live and to explore further avenues for treatment. My fieldwork in the Netherlands revealed that, many times, the patients did not ask for euthanasia. It was the doctor, a trusted General Practitioner whom the patient had known for many years, sometimes 30 or 40 years, who offered death to the patient with cancer. This practice may compromise the issue of voluntariness; it is difficult for many patients to contest the advice of a loyal General Practitioner. ${ }^{44}$ The GP may present before the patient the range of available options without manipulation, and with due respect for patient's life and wishes.

${ }^{44}$ Cohen-Almagor R, Should doctors suggest euthanasia to their patients? Reflections on Dutch perspectives, Theoretical Medicine and Bioethics. 2002; 23(4-5): 287-303. 
Guideline 3. The request for physician-assisted suicide of an adult, competent patient who suffers from an intractable, incurable and irreversible disease must be voluntary. ${ }^{45}$ The decision is that of the patient who asks to die without pressure, because life appears to be the worst alternative in the current situation. The patient should state this wish repeatedly over a period of time. We must verify that the request for physician-assisted suicide does not stem from a momentary urge, an impulse, a product of passing depression. This emphasis of enduring request is one of the requirements of the Dutch and Belgian legal guidelines. ${ }^{46}$ It should be ascertained with a signed document that the patient is ready to die now, rather than depending solely upon directives from the past.

Guideline 4. At times, the patient's decision might be influenced by severe pain. The Oregon Death with Dignity Act requires the attending physician to inform the patient of all

${ }^{45}$ See the Dutch requirements of careful practice, in Griffiths J, Bood A, and Weyers $\mathrm{H}$, Euthanasia and Law in the Netherlands. Amsterdam: Amsterdam University Press; 1998: p. 66. See also Chap. II. Article 3 of the Belgian Euthanasia Law. http://www.kuleuven.ac.be/cbmer/viewpic.php?LAN=E\&TABLE=DOCS\&ID=23 [Accessed 2 April 2015].

46 Termination of Life on Request and Assisted Suicide (Review Procedures) Act, 2002; Belgian Euthanasia Law 2002. 
feasible alternatives, including comfort care, hospice care and pain control. ${ }^{47}$ The proposed British Assisted Dying Bill (2014), prepared by Lord Falconer, requires that the patient "has been fully informed of the palliative, hospice and other care which is available to that person". ${ }^{48}$ Quality indicators in palliative care should be checked to ensure that the patient received adequate care from the caregivers. ${ }^{49}$

Guideline 5. The patient must be informed of the situation and the prognosis for recovery or escalation of the disease, with the suffering that it may involve. There must be an exchange of information between physicians and patients. ${ }^{50}$ Bearing this in mind, we

4713 Or. Rev. Stat. § 3.01 (1998). See Cohen-Almagor R, and Hartman MG, The Oregon Death with Dignity Act: Review and proposals for improvement. J. of Legislation. 2001; 27(2): 269-298; Schatman ME, Campbell A, (eds.), Chronic Pain Management: guidelines for multidisciplinary program development. NY: Informa Healthcare; 2007. 48 Assisted Dying Bill (2014), Section 3 "Declarations".

${ }^{49}$ Leemans K., Van den Block L., Vander Stichele R., et al., How to implement quality indicators successfully in palliative care services: perceptions of team members about facilitators of and barriers to implementation. Support Care Cancer (published online 2 April 2015).

50 On this issue, see Oregon Death with Dignity Act, Section 3, Attending physician responsibilities. Many bill proposals to legislate PAS in the United States specify certain information that must be communicated by the physician to the patient before honouring her request. See also Chap. II, Article 3 of the Belgian Euthanasia Law. 
should be careful to use neutral terms and to refrain from terms that might offend patients and their loved ones. ${ }^{51}$

Guideline 6. It must be ensured that the patient's decision is not a result of familial and environmental pressures. At times, patients may feel that they constitute a burden on their loved ones. It is the task of social workers to examine patients' motives and to see to what extent they are affected by various external pressures (as opposed to a truly free will to die). A situation could exist in which the patient is under no such pressure, but still does

51 Cohen-Almagor R, Language and reality at the end of life. J. of Law, Medicine and Ethics. 2000; 28(3) (Fall): 267-278; Bedell SE, Graboys TB, Bedell E, and Lown B, Words that harm, words that heal, Arch Intern Med. 2004; 164(13) (12 July): 1365-1368; The Consensus Statement on the Role of the Doctor, http://www.medschools.ac.uk/AboutUs/Projects/Documents/Role\%20of\%20Doctor\%20 Consensus\%20Statement.pdf [Accessed 2 April 2015]; General Medical Council, Tomorrow's $\quad$ Doctors $\quad$ (2009), $\quad$ http://www.gmcuk.org/Tomorrow_s_Doctors_0414.pdf_48905759.pdf [Accessed 2 April 2015]; Visser M, Deliens L, Houttekier D, Physician-related barriers to communication and patient- and family-centred decision-making towards the end of life in intensive care: a systematic review. Critical Care. 2014; 18: 604. See generally Joly Y, Knoppers BM (eds.), Routledge Handbook of Medical Law and Ethics. Abingdon: Routledge; 2015. 
not wish to be a burden on others. Obviously, we cannot say that the feelings of patients toward their loved ones are not relevant to the decision-making process. ${ }^{52}$

Guideline 7. The decision-making process should include a second opinion in order to verify the diagnosis and minimize the chances of misdiagnosis, as well as to allow the discovery of other medical options. A specialist, who is not dependent on the first physician, either professionally or otherwise, should provide the second opinion. ${ }^{53}$ The patient's attending physician, who supposedly knows the patient's case better than any other expert, must be consulted, and all reasonable alternative treatments must be explored. The Oregon Death with Dignity Act requires that a consulting physician shall examine the patient and her relevant medical records and subsequently confirm, in writing, the attending physician's diagnosis that "the patient is suffering from a terminal

${ }^{52}$ Cohen-Almagor R, The patients' right to die in dignity and the role of their beloved people, Annual Review of Law and Ethics. 1996; 4: 213-232 and Cohen-Almagor R, Fatal choices and flawed decisions at the End-of-Life: Lessons from Israel, Perspectives in Biology and Medicine. 2011; 54(4) (Autumn): 578-594; Hardwig J, Families and futility: Forestalling demands for futile treatment. J. of Clinical Ethics. 2005; 16(4): 328-337; Casarett DJ, Last Acts: Discovering Possibility and Opportunity at the End of Life. NY: Simon and Schuster; 2010.

${ }^{53}$ Chap. II, Article 3 of the Belgian Euthanasia Law, and Cohen-Almagor R, Euthanasia policy and practice in Belgium: Critical observations and suggestions for improvement, Issues in Law and Medicine. 2009; 24(3) (Spring): 187-218. 
disease." Furthermore, the consulting physician must verify that the patient is capable, is acting voluntarily, and has made an informed decision. ${ }^{54}$

Guideline 8 . It is advisable for the identity of the consultant to be determined by a small committee of specialists who will review the requests for physician-assisted suicide. This is in order to avoid the possibility of arranging deals between physicians ("you will consult for me regarding Mr. Jones, approving my decision, and I will consult for you regarding Ms. Smith, approving your decision"). ${ }^{55}$

54 Oregon Death with Dignity Act, Oregon Revised Statutes, Vol. 8 (1998 Supplement), at 981-982. The American Medical Association's council on ethical and judicial affairs suggests the participation of consultants to facilitate discussions that would help the parties reach a course of action. See Charatan F, AMA issues guidelines on end of life care. BMJ. 1999; 318 (March): 690.

55 In this context, for further discussion see Deschepper R, et. al, Communication on endof-life decisions with patients wishing to die at home: the making of a guideline for GPs in Flanders, Belgium. British J. of General Practice. 2006; 56 (January): 14-19, http://www.pubmedcentral.nih.gov/articlerender.fcgi?artid=1828069 [Accessed 2 April 2015]; Jansen-van der Weide MC, Onwuteaka-Philipsen BD, Van der Wal G, Implementation of the Project Support and Consultation on Euthanasia in The Netherlands (SCEN). Health Policy. 2004; 69(3): 365-373; de Diesbach E, de Loze M, 
Guideline 9. Some time prior to the performance of physician-assisted suicide, a physician and a psychiatrist are required to visit and examine the patient so as to verify that this is the genuine wish of a person of sound mind who is not being coerced or influenced by a third party. The conversation between the physicians and the patient should be held without the presence of family members in the room in order to avoid familial pressure. A date for the procedure is then agreed upon. The patient's loved ones will be notified so that they can be present right until the performance of the act, making the day an intimate, family occasion.

Guideline 10. The patient can rescind at any time and in any manner. This provision is granted under the Oregon Death with Dignity Act. ${ }^{56}$ Chapter III, Article 4 of the Belgian Euthanasia Law says that patients can withdraw or adjust their euthanasia declaration at

Brochier C, Montero E, Euthanasia in Belgium: 10 years on. Brussels: European Institute of Bioethics; 2012.

5613 Or. Rev. Stat. § 3.07 (1998). 
any time. ${ }^{57}$ The proposed British Assisted Dying Bill (2014) holds that the patient may revoke the aid-in-dying request at any time and that revocation need not be in writing. ${ }^{58}$

Guideline 11. Physician-assisted suicide may be performed only by a physician and in the presence of another physician. I am very much opposed to family members administering assisted-suicide (or euthanasia) as I think it can lead to abuse. The decision-making team should include at least two physicians and a lawyer who will examine the legal aspects involved and ensure there is protocol in place as a control mechanism against possible abuse. Perhaps a public representative should also be present during the entire procedure, including the decision-making process and the performance of physician-assisted suicide.

Guideline 12. Physician-assisted suicide may be conducted in one of three ways, all of which should be discussed openly and decided upon by the physician and the patient: (1) Oral medication; (2) Self-administered, lethal intravenous infusion; (3) Self-administered lethal injection. In this context I should note that some medication may be difficult or impossible for patients to ingest because of nausea or other side effects of the illness.

${ }^{57}$ Chamber of the Representatives of Belgium, Government Bill Related to Euthanasia (5 November 2001), Doc 5014488/001, project transmitted by the Senate. http://www.kuleuven.ac.be/cbmer/viewpic.php?LAN=E\&TABLE=DOCS\&ID=23

[Accessed 2 April 2015].

${ }^{58}$ Assisted Dying Bill (2014), Section 3 "Declarations" (6). 
The only exception in which the physician would be allowed to administer the lethal injection would occur in the event that medications have been provided and the patient's dying process is lingering on for long hours. Euthanasia should be allowed only after the failing of physician-assisted suicide, or if the patient cannot physically administer the lethal medication to herself.

Guideline 13. Physicians may not demand a special fee for the performance of assisted suicide. The motive for physician-assisted suicide is humane, so there must be no financial incentive and no special payment that might cause commercialization and promotion of such procedures. ${ }^{59}$

Guideline 14. There must be extensive documentation in the patient's medical file, including the disease diagnosis and prognosis by the attending and the consulting physicians; attempted treatments; the patient's reasons for seeking physician-assisted suicide; the patient's request in writing or documented on a video recording; documentation of conversations with the patient; the physician's offer to the patient to

59 In contrast, in Switzerland assisted-suicide is a business. See Dignitas founder is millionaire. Telegraph.co.uk $(24$ June 2010), http://www.telegraph.co.uk/news/worldnews/europe/switzerland/7851615/Dignitasfounder-is-millionaire.html [Accessed 2 April 2015]. 
rescind her request; documentation of discussions with her beloved people, and a psychological report confirming the patient's condition. ${ }^{60}$

Guideline 15. The drugs required to end one's life are known. As a control mechanism pharmacists should be required to file a report every time lethal medications are sold. Then it would be possible to track down the medication to the physician, and keep record of how many times physician-assisted suicide was performed.

Guideline 16. Physicians must not be coerced into taking actions that contradict their conscience or their understanding of their role. The proposed British Assisted Dying Bill (2014) holds that the health professional shall not be under any duty "to participate in anything authorised by this Act to which that person has a conscientious objection". ${ }^{61}$

Guideline 17. The local medical association should establish a committee, whose role will be not only to investigate the underlying facts that were reported but also to investigate whether there are "mercy" cases that were not reported and/or that did not comply with the Guidelines.

60 On the need for transparent reporting, see Smets T, Bilsen J, Cohen J et al., Reporting of euthanasia in medical practice in Flanders, Belgium: cross sectional analysis of reported and unreported cases. BMJ. 2010; 341: c5174.

${ }^{61}$ Assisted Dying Bill (2014), Section 5 "Conscientious objection". 
Guideline 18. Licensing sanctions will be taken to punish those health care professionals who violated the Guidelines, failed to consult or to file reports, engaged in involuntary termination of life without the patient's consent or with patients lacking proper decisionmaking capacity. Physicians who failed to comply with the above Guidelines will be charged and procedures to sanction them will be brought by the Disciplinary Tribunal of the Medical Association. The maximum penalty for violation of the Guidelines will be the revoking of the physician's medical license. In the event that this penalty proves insufficient in deterring potential abusers, there will be room to consider further penalties, including heavy fines and prison sentences. ${ }^{62}$

Guideline 19. An annual report should be published documenting all cases of aid-in-dying. The reports should be made available to the public. Discussions and debates about their findings should be promoted and encouraged.

\section{Conclusion}

We should give equal consideration to the interest of all patients. We should listen carefully to patients' preferences and their life (and death) objects. The culture of a

${ }^{62}$ For further deliberation, see Caplan AL, Snyder L, and Faber-Langendoen K, The role of guidelines in the practice of physician-assisted suicide. Annals of Internal Medicine. 2000; 132 (March): 476-481; Frileux S, Lelièvre C, Muñoz Sastre MT, Mullet E, Sorum PC, When is physician assisted suicide or euthanasia acceptable?, J. of Medical Ethics. 2003; 29(6) (December): 330-336. 
democratic society is based on two leading principles: do not harm others, and show respect and concern for others. We ought to show equal concern for each individual's good, as that individual defines what is good for her. Concern means giving equal weight to a person's life and autonomy. This is a combination of mind, body, and communication between the agent and those around her bed.

As we are talking on matters of life and death, diligence and care are paramount. We need to take the necessary measures to ensure that the best interests of the patients are served as they wished. Monitoring and control mechanisms should be in place to prevent potential abuse. Patients at the end of life are vulnerable. They require protection and assurance that their lives will not be terminating against their will. The medical profession should value the patients' autonomy and limit tendencies toward medical paternalism, ensuring that such tendencies do not trump the patients' wishes and best interests as defined by the patients themselves. Human lives are of great importance and value. Therefore the decision to end life should be made with utmost care and consideration, and with ample due process. 